\title{
Review Article \\ Comparative Study of Antenna Designs for RF Energy Harvesting
}

\author{
Sika Shrestha, ${ }^{1}$ Sun-Kuk Noh, ${ }^{2}$ and Dong-You Choi ${ }^{1}$ \\ ${ }^{1}$ Department of Information and Communication Engineering, Chosun University, 309 Pilmun-daero Dong-gu, \\ Gwangju 501-759, Republic of Korea \\ ${ }^{2}$ Department of Photoelectronics Information, Chosun College of Science and Technology, Republic of Korea
}

Correspondence should be addressed to Dong-You Choi; dychoi@chosun.ac.kr

Received 2 February 2012; Accepted 17 January 2013

Academic Editor: Hala A. Elsadek

Copyright (C) 2013 Sika Shrestha et al. This is an open access article distributed under the Creative Commons Attribution License, which permits unrestricted use, distribution, and reproduction in any medium, provided the original work is properly cited.

\begin{abstract}
In the last few years, several antenna designs of rectenna that meet various objectives have been proposed for use in RF energy harvesting. Among various antennas, microstrip patch antennas are widely used because of their low profile, light weight, and planar structure. Conventional patch antennas are rectangular or circular in shape, but variations in their basic design are made for different purposes. This paper begins with an explanation and discussion of different designs, put forward with an aim of miniaturization, harmonic rejection, and reconfigurability. Finally, microstrip patch structured rectennas are evaluated and compared with an emphasis on the various methods adopted to obtain a compact rectenna, harmonic rejection functionality, and frequency and polarization selectivity.
\end{abstract}

\section{Introduction}

As the demand for power increases, the need for alternate energy sources has become essential. Energy from external sources such as solar power, thermal energy, wind energy, and RF energy has been harvested for various purposes in the last few recent decades. Energy harvesting uses inexhaustible sources with little or no adverse environmental effect and can provide unlimited energy for the lifespan of electronic devices. The work presented here focuses on RF energy harvesting, in which the abundant RF energy from surrounding sources, such as nearby mobile phones, wireless LANs (WLANs), FM/AM radio signals, and broadcast television signals, is captured by a receiving antenna and rectified into a usable DC voltage.

Ambient RF energy is pervasive, especially that from mobile and Wi-Fi networks. ABI Research and IHS iSuppli estimated that the number of mobile phone subscriptions recently surpassed five billions, and the ITU estimated that there is more than one billion subscriptions for mobile broadband. Mobile phones represent a large source of transmitters from which to harvest RF energy and will potentially enable users to provide power-on-demand for a variety of closerange sensing applications. The number of Wi-Fi routers and wireless end-point devices such as laptops is also significant [1].

At short range (e.g., within the same room), a tiny amount of energy (microwatts) can be harvested from a typical Wi-Fi router transmitting at a power level of 50-100 mW. For longer-range operation, antennas with higher gain are needed for practical harvesting of RF energy from mobile base stations and broadcast radio towers. In 2005, Powercast demonstrated ambient RF energy harvesting at 1.5 miles $(\sim 2.4 \mathrm{~km})$ from a small, $5-\mathrm{kW}$ AM radio station. Subsequent demonstrations have included the harvesting of RF energy from an iPhone in the GSM band and from a nearby mobile base station [1].

We can categorize RF energy source into three general groups: intentional sources, anticipated ambient sources, and unknown ambient sources [2]. RF energy harvesting can be implemented as direct power for battery-free systems or battery activation, an auxiliary power source for battery recharging, or remote power with battery backup. A power source combined with energy harvesting can provide wireless 
devices with low maintenance cost or extended battery life by implementing the ability to receive power or charge the stored energy when needed, or to wake up remote sensors in sleep mode. The possibility of recycling the ambient electromagnetic energy especially in densely populated urban zones is actively being explored [3]. The major component used to convert this RF energy into utilizable DC power is a rectifying antenna, also termed as rectenna.

Among various entities of rectenna, antenna is one of the major elements which is responsible for collecting the incoming RF signals of various frequencies. The source of incoming RF energy can be WLAN $(2.4 \mathrm{GHz}, 5.8 \mathrm{GHz})$, WiMax, RFID (microwave band: 2.45, 5.8, 24.125 GHz) and so forth with various frequency ranges. Antennas with resonance at single or multiple applicable frequencies are designed with various ambitions. The variation made in antenna design that was designed with an aim of miniaturizing patch antenna, rejecting unwanted harmonics, and having reconfigurability in frequency and polarization is evaluated in this paper.

The paper is organized as follows. Rectennas are introduced briefly in Section 2. Several antenna designs of rectenna are discussed and compared with an emphasis on antenna size reduction, harmonic rejection, and reconfigurability in terms of frequency and polarization, in Sections 3, 4, and 5 , respectively.

\section{Rectennas}

A rectenna is a particular type of antenna that rectifies incoming electromagnetic waves into DC current. Over the last century, the development of rectennas for wireless power transmission and space solar power transmission has achieved great success in implementing specific functions and applications, such as RFID tagging systems, sensor batteries or capacitors, WLANs, WiMax, and cognitive radio systems, and also in medical applications.

A typical rectenna consists of four main components: antenna, prerectification filter, rectifying circuit, and DC pass filter. Figure 1 shows a block diagram of a typical rectenna. A microwave antenna collects incoming RF power. An input low-pass filter (LPF; prerectification filter) suppresses the unwanted higher harmonics rejected by the rectifying circuit and also provides matching between the antenna and the rectifier. A rectifying circuit rectifies the AC current induced in the antenna by the microwaves, and an output DC pass filter (postrectification filter) provides a DC path to the load by separating the high-frequency components from the DC signal.

A conventional rectenna consists of a dipole element or a mesh of dipoles that capture microwave energy and a Schottky diode for the rectification process. Several types of rectenna element have been proposed in the last few recent years. The antenna can be of any type, for example, dipole, Yagi-Uda, microstrip, monopole, loop, coplanar patch, spiral, or even parabolic. The rectenna can also take any type of rectifying circuit, such as a single shunt full-wave rectifier, a full-wave bridge rectifier, or another type of hybrid rectifier. A single diode in a serial configuration that also acts as a half-wave rectifier is the most common rectifying circuit. We can also use a half-wave parallel rectifier, a voltage doubler structure to theoretically double the output DC voltage, or a dual-diode full-wave rectifier to increase the conversion efficiency.

As the primary function of a rectenna is to convert $\mathrm{RF}$ energy to DC power, the main design challenge is to obtain high conversion efficiency, and there are basically two approaches to achieve this goal. The first option is to collect the maximum power and deliver it to the rectifying diode, and the second one is to suppress the harmonics generated by the diode that reradiate from the antenna as the power lost. In order to increase the conversion efficiency by the first method, several broadband antennas, large antenna arrays, and circularly polarized antennas have been designed. The broadband antenna receives relatively high RF power from various sources, and antenna array increases incident power delivered to the diode for rectification. Antenna array is an effective means of increasing the receiving power but a tradeoff arises between the antenna size and the radiation gain. The circularly polarized antenna offers power reception with less polarization mismatch. To increase the efficiency by second method, LPF is placed between antenna and rectifying circuit or antenna with the property of harmonic rejection is designed.

Among various types of antenna used in rectennas, microstrip patch antennas are gaining popularity for use in wireless applications owing to their low profile, light weight, low production cost, and being conformable to planer and nonplanar surface, simple, and inexpensive to manufacture using modern printed-circuit technology. The other reason for wide use of patch antenna is the versatility of patch antenna in terms of resonant frequency, polarization, pattern, and impedance when particular patch shape and mode are chosen. Therefore, they are extremely suitable for use as embedded antennas in handheld wireless devices and portable devices.

The rapid development of microstrip antenna technology began in the late 1970s. By the early 1980s, basic microstrip antenna elements and arrays were fairly well established in terms of design and modeling. The early work of Munson on microstrip antennas for use as a low profile flush mounted antennas on rockets and missiles showed that this was a practical concept for use in many antenna system problems. Various mathematical models were developed for this antenna, and its applications were extended to many other fields. A major contributing factor for advances of microstrip antennas is the revolution in electronic circuit miniaturization brought about by developments in largescale integration. As conventional antennas are often bulky and costly part of an electronic system, microstrip antennas based on photolithographic technology are seen as an engineering breakthrough.

In its most basic forms, a microstrip patch antenna consists of a radiating patch on one side of a dielectric substrate with a ground plane on the other side. Figure 2 shows a diagram of a simple rectangular patch antenna. The patch is generally made of a conducting material such as copper or gold and can take any possible shape, such as 


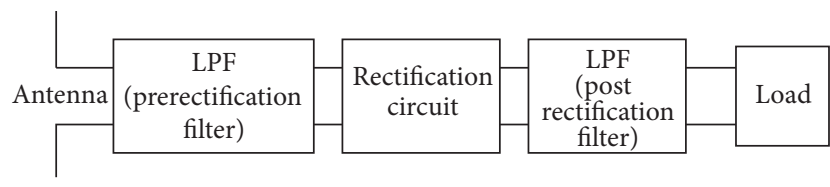

FIGURE 1: Block diagram of rectenna.

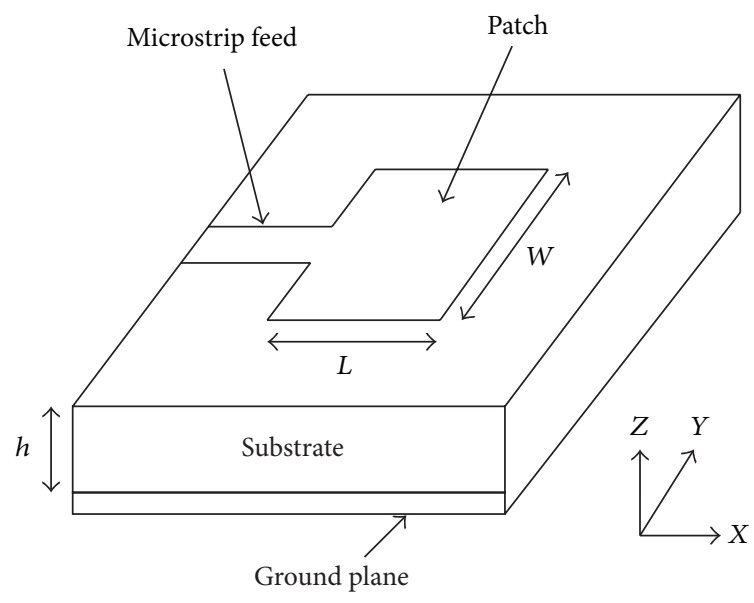

FIGURE 2: 3D view of rectangular patch antenna.

square, rectangular, thin strip (dipole), circular, elliptical, or triangular ones. Square, rectangular, dipole, and circular shapes are the most common because of ease of analysis and fabrication, and their attractive radiation characteristics, especially low cross-polarization radiation. The radiating patch and feed lines are usually photoetched on the dielectric substrate.

Several configurations can be used to feed microstrip antennas. The four most popular ones are the microstrip line, coaxial probe, aperture coupling, and proximity coupling. The microstrip feed line is a conducting strip usually of smaller width connected to the patch. It is easy to fabricate and simple to match by controlling the inset position but spurious radiation increases with the increase in substrate thickness that limits the bandwidth. In coaxial-line feeds, the inner conductor of the coax is attached to the radiation patch, and the outer conductor is attached to the ground plane. It is also easy to fabricate and match, and it has low spurious radiation, but it has narrow bandwidth and is difficult to model especially for thick substrate [4].

Aperture coupled feed consists of two substrates separated by the ground plane. The energy of the microstrip feed line present on the bottom side of the lower substrate is coupled to the patch through a slot on the ground plane separating the two substrates. The ground plane isolates the feed from radiation element and minimizes interference of spurious radiation. Proximity coupling has the largest bandwidth and low spurious radiation. The patch is present on top of the first substrate while the second substrate contains microstrip feed line on the upper side and the ground plane on the lower side in this technique [4].

\section{Antenna Miniaturization}

The design of compact antenna for rectennas has been inevitable to cope with the rapid growth of wireless applications. Several methods of reducing the size of microstrip antennas have been suggested. They include the use of high dielectric constant substrates, modification of the basic patch shapes, short circuiting the patch to the ground plane, and other techniques that combine these three methods. When high dielectric constant substrates are used, the guided wavelength underneath the patch is reduced; hence, the resonating patch size is also reduced. The reduction ratio is approximately related to the square root of the relative permittivity " $\varepsilon_{r}$ ". Employing high dielectric constant substrates is the simplest method of miniaturization, but the resulting antenna exhibits narrow bandwidth, high loss, and poor efficiency due to surface wave excitation. The modification of the basic patch shapes allows for substantial size reduction; however, some of these shapes will cause inefficient use of the available area. Shorting posts have been used in different arrangements to reduce the overall dimensions of the microstrip patch antenna. These shorting posts were modeled and analyzed as short pieces of transmission line with a series inductance and shunt capacitance [5].

This section is focused on the techniques adopted to reduce the size of the antenna through geometry optimization, slots with different shapes, or both of these techniques. Five miniaturized designs are shown in Figure 3. Figure 3(a) depicts a circular patch antenna with unbalance slots placed on the diameter line, having $45^{\circ}$ counter clockwise rotation of the vertical diameter with different size and position relative to the center of the circular disk. By introducing slots in the circular microstrip disk antenna at $2.45 \mathrm{GHz}$, the antenna radius is reduced from the calculated result of $16.5 \mathrm{~mm}$ to $15.5 \mathrm{~mm}$ of the proposed one, yielding $12 \%$ size reduction [6]. Figure 3(b) consists of a square aperture coupled patch antenna with a cross-shaped slot etched on its surface that permits a patch size reduction of $32.5 \%$. The rectenna has a compact size due to the use of a cross-shaped slot at the patch surface [7].

A two-port, meandered, square patch antenna with forty slits on the perimeter, ten on each side, is investigated at Figure 3(c) obtaining $48 \%$ reduction in size. Each group of slits is symmetrically placed with respect to the center of the side where it belongs. The slits disturb the currents flowing on the surface, forcing them to meander and thus increasing the electrical length of the patch antenna in both dimensions. Accordingly, the operating frequency decreases, whereas the physical size of the patch is unaffected. In the similar manner, operation at a fixed frequency with reduced size is possible by increasing the slit length [8]. A square patch with two orthogonal pairs of irregular and unsymmetrical slits is proposed in Figure 3(d). The presence of slits in this antenna is a way to increase the surface current path length compared with that of the conventional square patch 


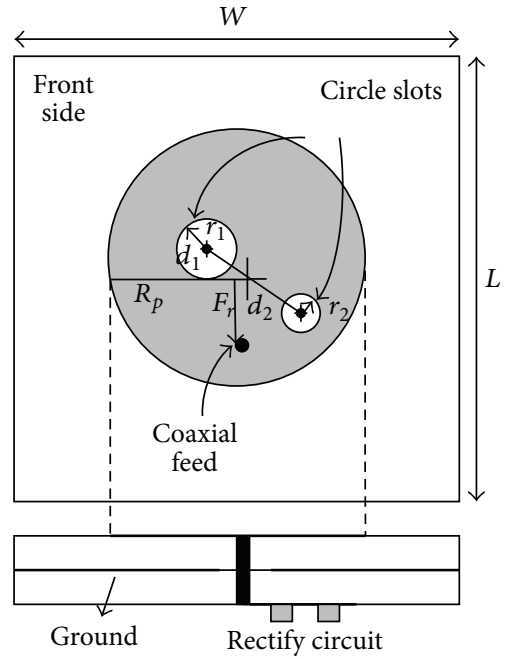

(a)

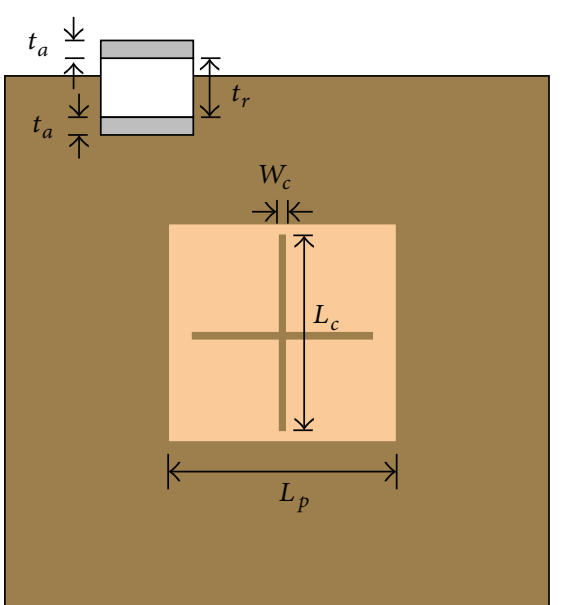

(b)

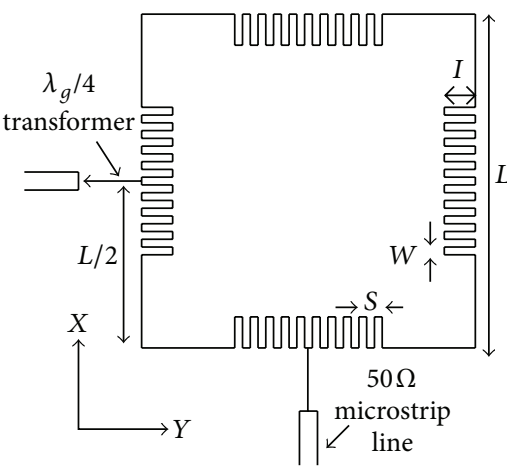

(c)

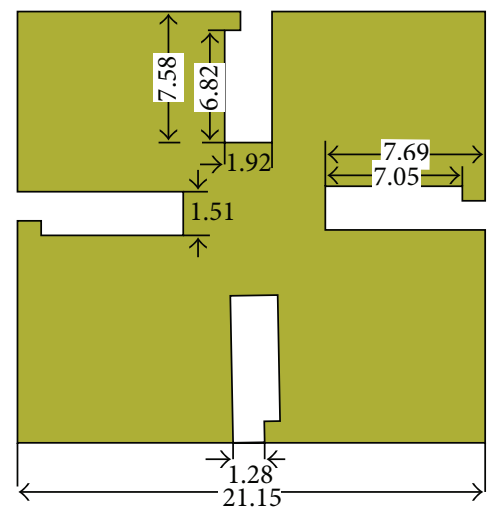

(d)

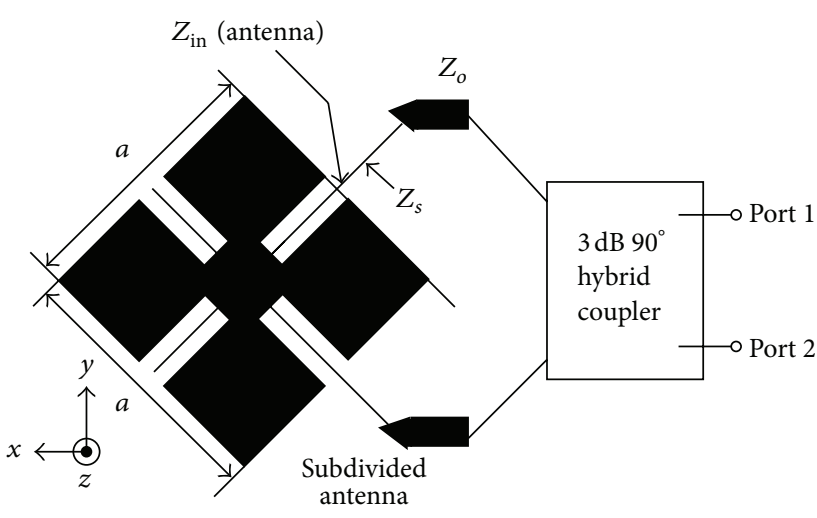

(e)

FIGURE 3: Various miniaturized antenna designs.

antenna and to reduce the size to $40 \%$ [9]. The antenna shown in Figure 3(e) is composed of the interconnection of four corner patches alternating with four strips and a fifth central patch representing a surface reduction of $60 \%$. The resonance frequency in the proposed antenna is significantly lowered by the subdivided nature of the metal geometry, which introduces longer current paths along its contours, and simultaneously by the strong inductive/capacitive loadings associated with the branch/gap elements [10].

The aforementioned designs were miniaturized by modifying the basic patch shapes and embedding suitable slots in the radiating patch. The application of modifying the conventional antenna and placing slots is to increase their electrical length that lengthens the surface current paths and causes a shift in the resonance frequency. Thus, by reducing the dimensions of the patch, we can get much more compact antenna than their conventional counterpart with the same resonance frequency. We compared the various ways of modifying the conventional patch antenna to obtain small sized antenna. Table 1 briefly does the comparison of Figures 3(a), 3(b), 3(c), 3(d), and 3(e) on the basis of changes done on their basic shape and their corresponding percentage of size reduction, whose detailed description is present in [610], respectively.

\section{Harmonic Rejection}

Rectifying circuits are used in rectennas to rectify the AC current induced in the antenna by microwaves. The nonlinear components of rectifying circuits, such as diodes, generate harmonics of the fundamental frequency. These unwanted harmonics cause harmonic reradiation and electromagnetic interference with nearby circuits and antennas and reduce efficiency. Therefore, microwave components such as an LPF must be added between the antenna and the diode to suppress these harmonics that improves system performance and prevent harmonic interference. Several rectenna designs having harmonic-rejecting antennas have been proposed to reduce the size and cost by eliminating the prerectification filter. With the removal of prerectification filter, the additional insertion loss at the fundamental frequency associated with it can be eliminated, increasing the efficiency. Hence, the antenna with the harmonic rejection functionality will bring 


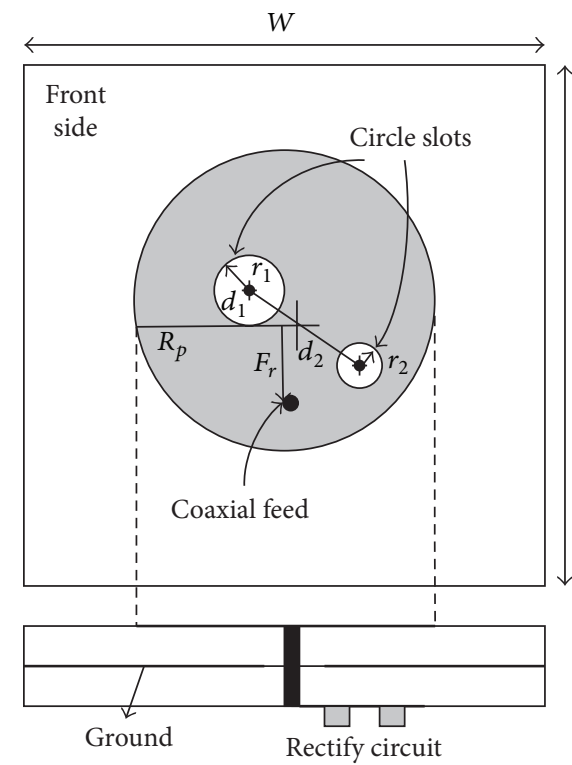

(a)

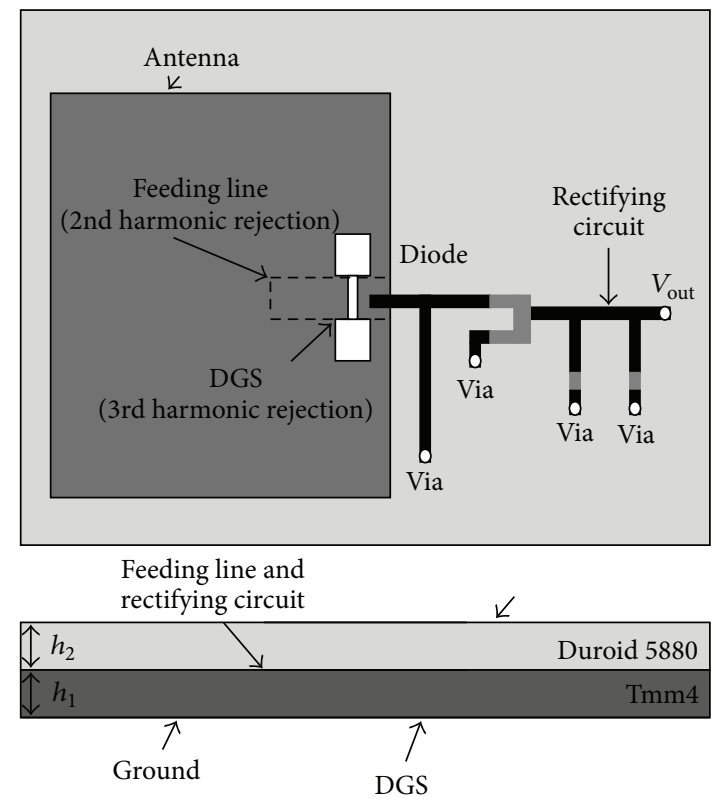

(c)

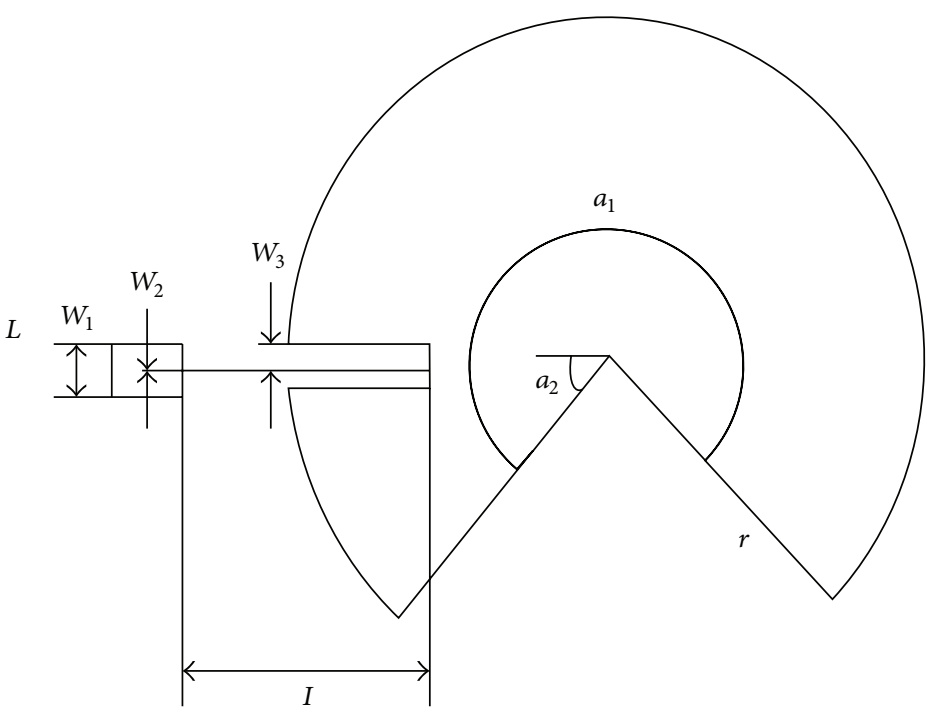

(b)

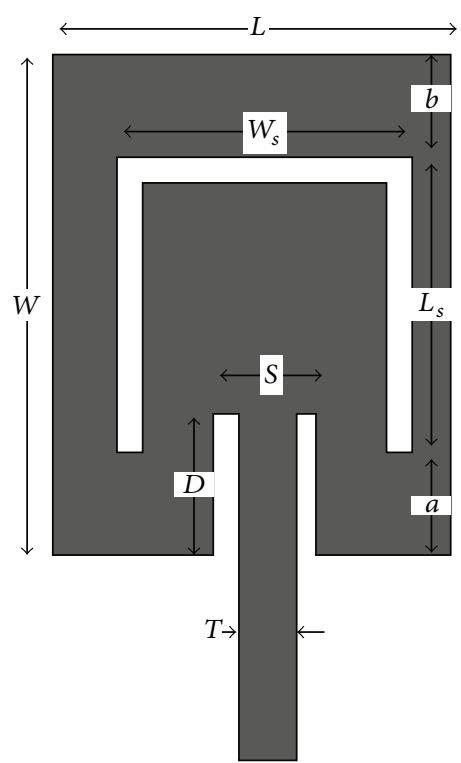

(d)

FIgURE 4: Various antenna designs for harmonic rejection.

the advantages of low cost, simpler design, and conversion efficiency enhancement.

Some of the designs having the behavior of harmonic rejection are shown in Figure 4. Figure 4(a) is similar to Figure 3(a), where the unbalanced slot can achieve second harmonic rejection too omitting the requirement of LPF [6]. The diode of rectenna with microstrip square patch antenna operating at $2.4 \mathrm{GHz}$ creates harmonics such as 4.8 and $7.2 \mathrm{GHz}$, but a microstrip circular-sector antenna with a circular sector angle of $240^{\circ}$ and a feeding angle of $30^{\circ}$ from the edge of the circular sector as shown in Figure 4(b) blocks these second and third harmonics from reradiation [11]. Rectangular patch antenna with dumbbell-shaped slot on the ground plane also called as defected ground structure (DGS) resonating at $2.45 \mathrm{GHz}$ as depicted in Figure 4(c) has return loss of $-1.95 \mathrm{~dB}$ and $-1.75 \mathrm{~dB}$ at the harmonics frequencies $4.9 \mathrm{GHz}$ and $7.35 \mathrm{GHz}$, respectively [12]. Figure $4(\mathrm{~d})$ is an inset fed u-slot antenna at $2.4 \mathrm{GHz}$ which exhibits high reflection coefficient at the second and third harmonics. The length of the inset in the particular point not only causes deep 


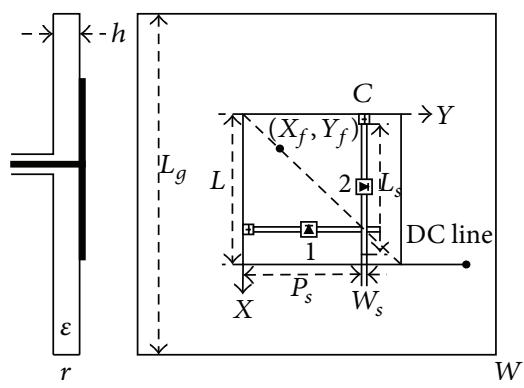

(a)

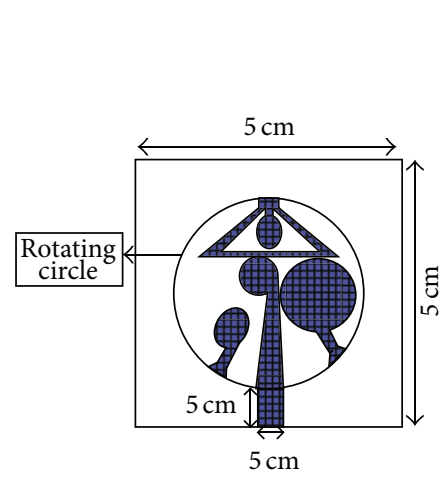

(d)

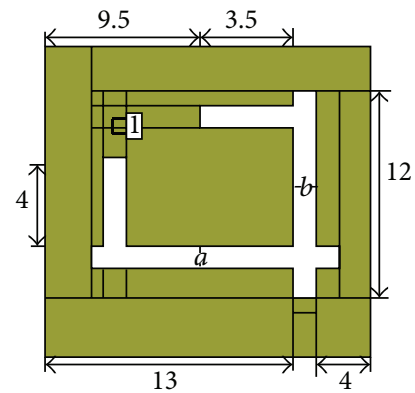

(b)

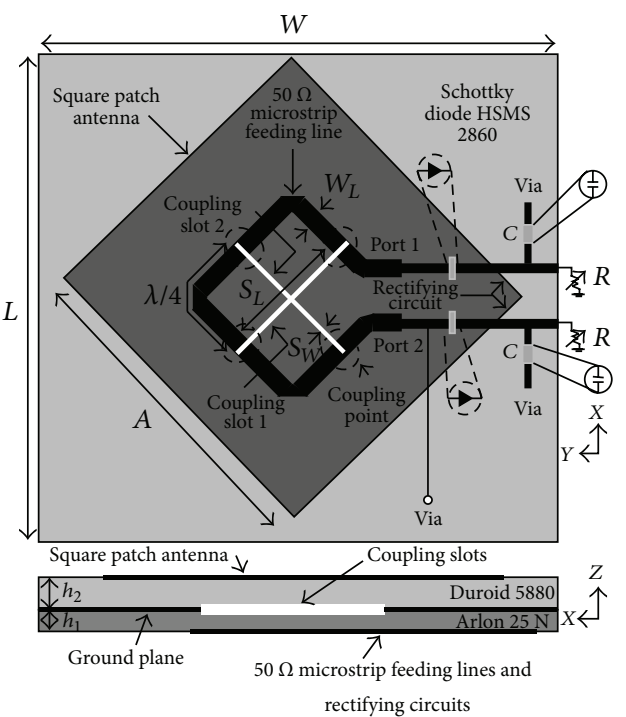

(c)

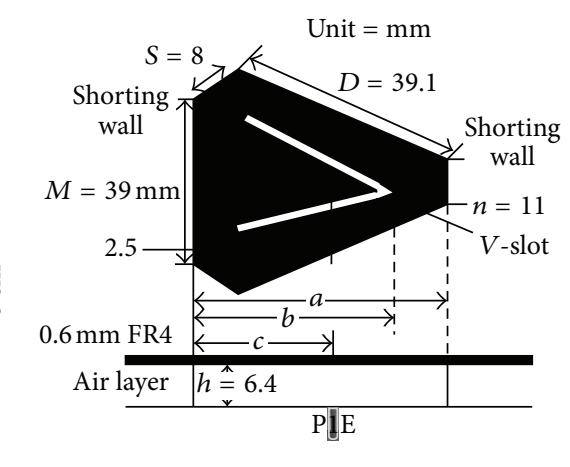

(e)

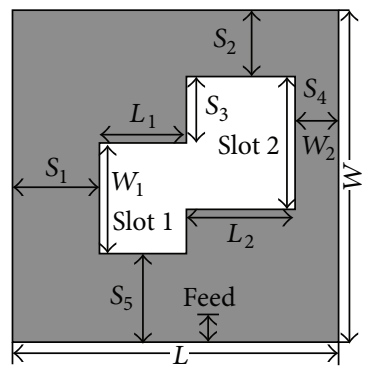

(f)

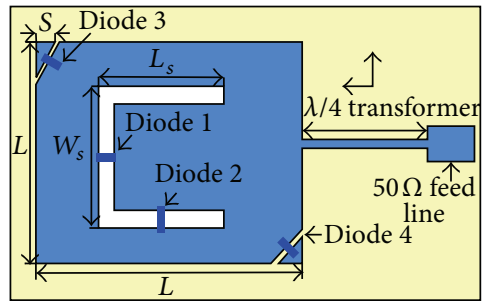

(g)

FIGURE 5: Various antennas designed for reconfigurability.

resonance of the antenna in the desired frequency but also suppresses harmonics increasing the efficiency of the system [13].

It is also seen that along with rejecting harmonics the antennas presented in Figure 4 also have higher gain than the conventional antennas. Comparison made between Figures 4(a), 4(b), 4(c), and 4(d) on the basis of modified shape with the cause behind the harmonic rejection, their corresponding gain, and conversion efficiency is shown in Table 2. These antennas are described in detail in $[6,11-13]$, respectively.

\section{Reconfigurable Antennas}

Reconfigurable antennas have received much attention in RF energy harvesting models owing to their selectivity for operating frequency and polarization. The characteristic of having frequency selectivity and polarization selectivity can be termed as frequency diversity and polarization diversity, respectively. Frequency diversity accommodates multiband or wideband frequency ranges and automatic frequency tuning. A reconfigurable microstrip antenna can achieve 
TABLE 1: Various antenna shapes and size reduction.

\begin{tabular}{lllll}
\hline Figure & Antenna shape & Freq. & Substrate & $\begin{array}{c}\text { Size reduction } \\
(\%)\end{array}$ \\
\hline 3(a) & $\begin{array}{l}\text { Circular patch with slots placed on the diameter } \\
\text { 3(b) }\end{array}$ & $\begin{array}{l}\text { Square patch with cross-shaped slot etched on its } \\
\text { surface }\end{array}$ & $2.45 \mathrm{GHz}$ & $\begin{array}{l}\text { FR-4 substrate }\left(\varepsilon_{r}=4.4\right) \\
\text { Two Arlon A25N substrates separated } \\
\text { by ROHACELL 51 foam layer }\end{array}$ \\
3(c) $\quad \begin{array}{l}\text { Forty slits on the perimeter of a square patch, ten } \\
\text { on each side }\end{array}$ & $2.45 \mathrm{GHz}$ & Taconic, TLY-5 laminate $\left(\varepsilon_{r}=2.21\right)$ \\
3(d) $\quad \begin{array}{l}\text { Square patch with two orthogonal pairs of } \\
\text { irregular, unsymmetrical slits }\end{array}$ & $\begin{array}{l}\text { GPS design } \\
\text { frequency }\left(L_{1}\right)\end{array}$ & RT/Duroid 6010 LM substrate $\left(\varepsilon_{r}=10.2\right)$ \\
3(e) $\quad \begin{array}{l}\text { Square patch with interconnection of four corner } \\
\text { patches alternating with four strips and a fifth } \\
\text { central patch }\end{array}$ & $5.85 \mathrm{GHz}$ & RT/Duroid 5870 substrate $\left(\varepsilon_{r}=2.33\right)$ \\
\hline
\end{tabular}

TABLE 2: Various antenna shapes and the associated harmonic rejection

\begin{tabular}{|c|c|c|c|c|c|}
\hline Figure & Shape & Freq. & Harmonic rejection & Gain & Conversion efficiency \\
\hline $4(\mathrm{a})$ & $\begin{array}{l}\text { Circular patch with slots on } \\
\text { the diameter }\end{array}$ & $2.45 \mathrm{GHz}$ & $\begin{array}{l}\text { Unbalanced slots achieve } \\
\text { second harmonic rejection }\end{array}$ & $\begin{array}{l}3.36 \mathrm{dBic} \\
\mathrm{CP} \text { gain }\end{array}$ & $\begin{array}{l}\text { Efficiency would reach } 53 \% \text { and } \\
75 \% \text { with } 1 \mathrm{~K} \text { resistor load under } \\
\text { ANSI/IEEE uncontrolled and } \\
\text { controlled RF human exposure } \\
\text { limit, respectively. }\end{array}$ \\
\hline $4(b)$ & $\begin{array}{l}\text { Microstrip circular sector } \\
\text { antenna }\end{array}$ & $2.4 \mathrm{GHz}$ & $\begin{array}{l}\text { Circular sector antenna } \\
\text { with sector angle of } 240^{\circ} \\
\text { and inset feeding point at } \\
30^{\circ} \text { from the edge avoids } \\
\text { harmonic radiation }\end{array}$ & $4.677 \mathrm{dBi}$ & $\begin{array}{l}\text { Maximum efficiency of } 77.8 \% \text { is } \\
\text { achieved with a load resistor of } \\
150 \Omega \text { and input power of } 10 \mathrm{dBm}\end{array}$ \\
\hline $4(\mathrm{c})$ & $\begin{array}{l}\text { Rectangular patch with } \\
\text { DGS }\end{array}$ & $2.45 \mathrm{GHz}$ & $\begin{array}{l}\text { An optimized length of the } \\
\text { feeding line and DGS are } \\
\text { used to reject the second } \\
\text { and third harmonics }\end{array}$ & $6.4 \mathrm{~dB}$ & $\begin{array}{l}\text { Conversion efficiency is } 74 \% \\
\text { using a } 1300 \Omega \text { load resistor at a } \\
\text { power density of } 0.3 \mathrm{~mW} / \mathrm{cm}^{2}\end{array}$ \\
\hline $4(d)$ & $\begin{array}{l}\text { U-shaped slot in middle } \\
\text { surface of inset-fed } \\
\text { rectangular patch antenna }\end{array}$ & $2.4 \mathrm{GHz}$ & $\begin{array}{l}\text { U-slot antenna with inset } \\
\text { feeding suppresses the } \\
\text { harmonics }\end{array}$ & $6.96 \mathrm{dBi}$ & Not specified \\
\hline
\end{tabular}

polarization diversity among linear polarization (LP), righthand circular polarization (RHCP), and left-hand circular polarization (LHCP). RF reconfigurability is basically achieved by dynamically altering the physical structure of the antenna by connecting and/or disconnecting different parts of the antenna structure that interact with its radiation properties and thereby alter its RF response.

A multiband antenna is needed in order to avoid using two antennas and to allow simultaneous transmission of video, voice, and data information. It can be realized by frequency diversity, which increases the power output, potentially expands the mobility options, and simplifies installation. Two approaches are typically used to obtain wideband frequency ranges: the use of stacked patches and the activation of different modes of the patch. The first approach incorporates a multilayered patch substrate that will resonate at different frequencies. However, this method increases the height of the antenna. The second approach achieves dualfrequency operation by activating two modes under the patch, such as the $\mathrm{TM}_{10}$ and $\mathrm{TM}_{30}$ modes or the $\mathrm{TM}_{10}$ and $\mathrm{TM}_{01}$ modes.
The patch elements radiate primarily linear polarized waves; however, by using various feed arrangements with slight modifications of the elements, circular and elliptical polarization can be obtained. Circular polarization can be obtained if two orthogonal modes are excited with a $90^{\circ}$ time-phase difference between them. Circular polarization can be LHCP or RHCP. A circularly polarized system is more suitable in several cases because of its insensitivity to transmitter and receiver orientation; for instance, in rotating platforms, circularly polarized rectennas help in achieving the same DC voltage irrespective of rectenna rotation, thus avoiding polarization mismatch and loss. The polarization diversity of reception is important for countering the effects of detrimental fading loss caused by multipath effects and for achieving a high degree of polarization control in order to optimize the system performance.

The design of reconfigurable antennas requires the inclusion of certain switching elements. These elements perform the job of connecting different parts of the antenna. This allows the antenna's shape to be modified, which causes a corresponding change in its $\mathrm{RF}$ response (return loss/radiation 
TABLE 3: Various antenna shapes and their reconfigurability.

\begin{tabular}{|c|c|c|c|c|c|}
\hline Figure & Antenna shape & Freq. & $\begin{array}{l}\text { Reconfigurable } \\
\text { feature }\end{array}$ & Cause of reconfigurability & Application \\
\hline $5(a)$ & $\begin{array}{l}\text { Square patch with orthogonal slots } \\
\text { and two pin diodes on the slots }\end{array}$ & $4.64 \mathrm{GHz}$ & $\begin{array}{l}\text { Polarization } \\
\text { diversity (LHCP } \\
\text { or RHCP) }\end{array}$ & $\begin{array}{l}\text { By turning the diodes on or off, } \\
\text { either RHCP or LHCP can be } \\
\text { obtained with the same feeding } \\
\text { probe, which is located on the } \\
\text { diagonal line of the patch }\end{array}$ & $\begin{array}{l}\text { WLANs, satellite } \\
\text { links, and space } \\
\text { robots }\end{array}$ \\
\hline $5(\mathrm{~b})$ & $\begin{array}{l}\text { Square patch consisting of two } \\
\text { orthogonal L-shaped slots with } \\
\text { two pin diodes on the slots }\end{array}$ & $\begin{array}{l}4.44 \mathrm{GHz} \text { and } \\
4.49 \mathrm{GHz}\end{array}$ & $\begin{array}{l}\text { Polarization } \\
\text { diversity (LHCP } \\
\text { or RHCP) }\end{array}$ & $\begin{array}{l}\text { Reconfigurability is achieved by } \\
\text { switching two pin diodes. In } \\
\text { RHCP antenna, diode a is turned } \\
\text { ON, and diode b is turned OFF; } \\
\text { in LHCP antenna, diode b is } \\
\text { turned ON, and diode a is turned } \\
\text { OFF. }\end{array}$ & $\begin{array}{l}\text { Unlicensed and } \\
\text { licensed WiMax } \\
\text { (IEEE 802.16a), } \\
\text { future planetary } \\
\text { missions, and } \\
\text { satellite links }\end{array}$ \\
\hline $5(\mathrm{c})$ & $\begin{array}{l}\text { Square patch coupled to a } \\
\text { microstrip line by an aperture in } \\
\text { the ground plane }\end{array}$ & $2.45 \mathrm{GHz}$ & $\begin{array}{l}\text { Polarization } \\
\text { diversity (LHCP } \\
\text { or RHCP) }\end{array}$ & $\begin{array}{l}\text { Reconfigurability is obtained by } \\
\text { selecting one of two excitation } \\
\text { points and terminating the other } \\
\text { with a } 50 \text {-resistive load. RHCP is } \\
\text { obtained if the excitation point is } \\
\text { located on Port } 1 \text {, and LHCP is } \\
\text { obtained if the antenna is fed at } \\
\text { Port } 2\end{array}$ & Not available \\
\hline $5(d)$ & $\begin{array}{l}\text { A circular patch rotates to feed } \\
\text { different shapes. The rotating } \\
\text { circular part includes three } \\
\text { circular patches and one slotted } \\
\text { triangle }\end{array}$ & $\begin{array}{l}\text { Covers five } \\
\text { different bands } \\
\text { (from } 2 \mathrm{GHz} \text { up } \\
\text { to } 7 \mathrm{GHz} \text { ) }\end{array}$ & $\begin{array}{l}\text { Frequency } \\
\text { diversity }\end{array}$ & $\begin{array}{l}\text { Reconfigurability is achieved by } \\
\text { rotational motion of part of the } \\
\text { antenna patch. With every } \\
\text { rotation, a different antenna } \\
\text { structure is fed in order to } \\
\text { produce a different set of } \\
\text { resonant frequencies }\end{array}$ & $\begin{array}{l}\text { Cognitive radio } \\
\text { systems }\end{array}$ \\
\hline $5(e)$ & $\begin{array}{l}\text { Short-circuited triangular patch } \\
\text { antenna with truncated corner } \\
\text { having two shorting walls and a } \\
\text { V-shaped slot patch }\end{array}$ & $\begin{array}{c}2.5-2.55 \mathrm{GHz} \\
\text { and } 3.4-3.7 \mathrm{GHz} \\
\text { WiMax bands }\end{array}$ & $\begin{array}{l}\text { Frequency } \\
\text { diversity }\end{array}$ & $\begin{array}{l}\text { By placing two shorting walls } \\
\text { with a V-shaped slot patch, two } \\
\text { resonant modes can be excited } \\
\text { simultaneously, yielding } \\
\text { frequency diversity }\end{array}$ & $\begin{array}{l}\text { Covers } 2.5-2.55 \mathrm{GHz} \\
\text { and } 3.4 \text { to } 3.7 \mathrm{GHz} \\
\text { WiMax bands }\end{array}$ \\
\hline $5(f)$ & $\begin{array}{l}\text { Two rectangular slots properly } \\
\text { positioned along the diagonal of a } \\
\text { square patch antenna }\end{array}$ & $\begin{array}{l}5.15-5.35 \mathrm{GHz} \\
\text { and } 5.5 \mathrm{GHz}\end{array}$ & $\begin{array}{l}\text { Frequency } \\
\text { diversity and } \\
\text { polarization } \\
\text { diversity (LHCP } \\
\text { or RHCP) }\end{array}$ & $\begin{array}{l}\text { Positioning the slots along the } \\
\text { left diagonal and right diagonal } \\
\text { generates RHCP and LHCP, } \\
\text { respectively }\end{array}$ & $\begin{array}{l}\text { Can function as a } \\
\text { rectenna for wireless } \\
\text { battery charging at } \\
5.5 \mathrm{GHz} \text { and data } \\
\text { telemetry in the } \\
5.15-5.35 \mathrm{GHz} \\
\text { WLAN band }\end{array}$ \\
\hline $5(\mathrm{~g})$ & $\begin{array}{l}\text { Square patch with two pin diodes } \\
\text { on a U-slot along with two diodes } \\
\text { on the truncated corners }\end{array}$ & $\begin{array}{l}2.415 \mathrm{GHz} \\
\text { and } 2.650 \mathrm{GHz}\end{array}$ & $\begin{array}{l}\text { Frequency } \\
\text { diversity and } \\
\text { polarization } \\
\text { diversity (LP, } \\
\text { LHCP, or } \\
\text { RHCP) }\end{array}$ & $\begin{array}{l}\text { The switching of the PIN diode } \\
\text { on the U-slot realizes frequency } \\
\text { diversity and polarization } \\
\text { diversity among LP, RHCP, and } \\
\text { LHCP is obtained by switching } \\
\text { three PIN diodes on the slot and } \\
\text { the truncating corners of a } \\
\text { square patch on and off }\end{array}$ & $\begin{array}{l}\text { WLAN/digital } \\
\text { multimedia } \\
\text { broadcasting } \\
\text { applications }\end{array}$ \\
\hline
\end{tabular}

pattern). The switching job can be performed by lumped elements (capacitors/inductors), RF microelectromechanical systems, PIN diodes, or photoconductive switches. The use of these switching elements (except the photoconductive switches) requires the design of an appropriate biasing network for activation and deactivation [14]. Photoconductive switches usually require a high laser pumped power level to excite sufficient electrons from the valence band to the conduction band to make the switch conductive [15].
Several techniques have been explored, and various approaches have been proposed for the methods of obtaining reconfigurable antennas. This section highlights various methods adopted for the diversity in terms of frequency and polarization, in microstrip patch antennas that have been used as reconfigurable rectennas. Seven different designs proposed for either frequency diversity or polarization diversity or both are shown in Figure 5. Among these figures, the first three designs exhibit polarization diversity, the fourth and 
fifth designs demonstrate frequency diversity, and the last two designs reveals both frequency and polarization diversity.

Square patch antenna having two orthogonal slots and two pin diodes at the center of the slot is shown in Figure 5(a). When diode on the horizontal slot is on and diode on vertical slot is off, the radiation fields of the $\mathrm{TM}_{10}$ and $\mathrm{TM}_{01}$ mode have the same magnitude and $90^{\circ}$ out of phase at a midpoint frequency, generating RHCP pattern. Similarly for the opposite scenario, the roles of the modes are reversed and LHCP pattern can be obtained [16]. Figure 5(b) consists of square patch antenna incorporated by two L-shaped slots having pin diodes inserted in these slots. This design also adopts the similar way of obtaining polarization diversity, by making diodes "a" and "b" ON and OFF, respectively, for LHCP and vice versa for RHCP [17].

The third design evaluated in this paper for polarization diversity is shown in Figure 5(c). In this design, the microstrip feeding line is coupled to the square patch antenna through a cross-slot etched on the ground plane. For polarization diversity, two feeding accesses are chosen arbitrarily. When the excitation point is located on port 2, the opposed coupling points on slot 2 have a peak of excitation current in phase while the opposed coupling points on slot 1 have a null of magnetic current. After a quarter period, the excitation current is totally inverted and opposed coupling points have a null of magnetic current on slot 2 and are maximum on slot 1 . This provides two linear polarizations with a phase difference of $90^{\circ}$. LHCP polarization is then emitted, and RHCP is emitted when excitation is located at port 1 [18].

Figures 5(d) and 5(e) are designed with the purpose of frequency reconfigurability. In Figure 5(d), the frequency tuning is achieved through rotational motion of the circular patch that contains four different shapes corresponding to a different set of resonant frequencies. The different RF shapes are three circular patches and one slotted triangle. The four sets of frequencies, "2.4-2.6 GHz," "2.6-3.4 GHz" " 4 $5 \mathrm{GHz}$," and " $3-4 \mathrm{GHz} / 5.26-7 \mathrm{GHz}$," are covered by the four different shapes [19]. A triangular-shaped corner truncated short-circuited antenna with $\mathrm{V}$-shaped slot for dual band operation (2.5-2.55 GHz and 3.4 to $3.7 \mathrm{GHz}$ WiMax bands) is proposed in Figure 5(e). The two resonant modes are excited simultaneously by placing two shorting walls with a V-shaped slot in the patch [20].

The patch antenna can have both the feature of polarization diversity and frequency diversity. Figure 5(f) displays a circularly polarized microstrip patch antenna which can function as wireless battery charging at $5.5 \mathrm{GHz}$ and data telemetry in the $5.15-5.35 \mathrm{GHz}$ WLAN band. This dualband and dual-polarized antenna is a square patch antenna containing two rectangular slots properly positioned along its diagonal. The two slots positioned along the left diagonal of the microstrip patch antenna generate RHCP and along the right diagonal generate LHCP [21].

The last design of Figure 5 is also a patch antenna with frequency and polarization diversities. It consists of a corner truncated square patch incorporating $\mathrm{U}$-slot and pin diodes, as shown in Figure 5(g). Frequency diversity is achieved by controlling the electrical length through the switching of the pin diode on the U-slot. When all diodes are off it operates at resonant frequency of $2415 \mathrm{MHz}$. It operates at $2650 \mathrm{MHz}$ in three situations: when all diodes are on, when diodes 1, 3, and 4 are on and diode 2 is off, and when diode 1 is on and diodes 2, 3, and 4 are off. Polarization diversity is achieved by switching pin diodes on the slot and truncated corners. If diodes 1,3 , and 4 are turned on and diode 2 is turned off it exhibits LP characteristic. RHCP characteristic is exhibited when diode 1 is turned on and diodes 2, 3, and 4 are turned off. If all diodes are on, then LHCP is emitted [22].

A comparison between the abovementioned seven figures of Figure 5 was performed. These antennas having the option of either polarization selectivity or frequency selectivity or both have found application in several areas. Table 3 depicts the comparison of these figures in terms of antenna shape, operating frequency, brief summary of the reason behind the cause of reconfigurability, and their application. The details of these antennas shown in Figures 5(a), 5(b), 5(c), 5(d), 5(e), $5(\mathrm{f})$, and $5(\mathrm{~g})$ are present in [16-22], respectively.

\section{Conclusions}

Antenna being a vital component of rectenna, the modification on its design can yield a compact size, suppress unwanted harmonics, and provide frequency and polarization diversity. Among various antennas used in rectenna, microstrip patch antenna is chosen for the evaluation and comparison because of its simplicity and easy fabrication. Various forms of microstrip patch antenna different from the conventional shape are analyzed with the explanation of the modification made in the design to obtain reduced size, harmonic rejection functionality, and reconfigurability in polarization and frequency. This attempt can be helpful to understand the behavior of patch antenna in different circumstances. We hope that this work will be helpful for researchers who are interested in improving rectenna design to obtain better RF energy harvesting performance.

\section{Acknowledgment}

This study was supported by a research fund from the Chosun University, 2012.

\section{References}

[1] http://www2.electronicproducts.com/RF_energy_harvesting and_wireless_power-article-FAJH_Energy_Aug2011-html.aspx.

[2] S. Kim, "RF Energy Harvesting techniques for wirelessly powered devices," in Proceedings of the IEEE MTT-S International Microwave Workshop Series on Intelligent Radio for Future Personal Terminals (IMWS-IRFPT '11), Daejeon, Republic of Korea, 2011.

[3] Y. Kawahara, K. Tsukada, and T. Asami, "Feasibility and potential application of power scavenging from environmental RF signals," in Proceedings of the IEEE International Symposium on Antennas and Propagation and USNC/URSI National Radio Science Meeting, (APSURSI '09), Charleston, SC, USA, June 2009.

[4] C. A. Balanis, Antenna Theory Analysis \& Design, John Wiley \& Sons, New York, NY, USA, 2nd edition, 1997. 
[5] E. Krantz, S. Riley, and P. Large, "The design and performance of the zephyr geodetic antenna," in Proceedings of the 14th International Technical Meeting of the Satellite Division of The Institute of Navigation (ION GPS '01), pp. 1942-1951, Salt Lake City, Utah, 2001.

[6] T. C. Yo, C. M. Lee, C. M. Hsu, and C. H. Luo, "Compact circularly polarized rectenna with unbalanced circular slots," IEEE Transactions on Antennas and Propagation, vol. 56, no. 3, pp. 882-886, 2008.

[7] G. A. Vera, A. Georgiadis, A. Collado, and S. Via, "Design of a $2.45 \mathrm{GHz}$ rectenna for electromagnetic (EM) energy scavenging," in Proceedings of the IEEE Radio and Wireless Symposium, (RWW'10), pp. 61-64, January 2010.

[8] D. T. Notis, P. C. Liakou, and D. P. Chrissoulidis, "Dual polarized microstrip patch antenna, reduced in size by use of peripheral slits," in Proceedings of the 7th European Conference on Wireless Technology, (ECWT '04), pp. 273-276, October 2004.

[9] J. K. Ali, "A new compact size microstrip patch antenna with irregular slots for handheld gps application," Engineering \& Technology, vol. 26, no. 10, 2008.

[10] J. Y. Park, C. Caloz, Y. Qian, and T. Itoh, "A compact circularly polarized subdivided microstrip patch antenna," IEEE Microwave and Wireless Components Letters, vol. 12, no. 1, pp. 18-19, 2002.

[11] J. Y. Park, S. M. Han, and T. Itoh, "A rectenna design with harmonic-rejecting circular-sector antenna," IEEE Antennas and Wireless Propagation Letters, vol. 3, no. 1, pp. 52-54, 2004.

[12] Z. Harouni, L. Osman, and A. Gharsallah, "Efficient 2. $45 \mathrm{GHz}$ rectenna design with high harmonic rejection for wireless power transmission," International Journal of Computer Science, vol. 7, no. 5, 2010.

[13] R. Dehbashi, Z. Atlasbaf, and K. Forooraghi, "New compact size microstrip antennas with harmonic rejection," IEEE Antennas and Wireless Propagation Letters, vol. 5, no. 1, pp. 395-398, 2006.

[14] D. E. Anagnostou, G. Zheng, M. T. Chryssomallis et al., "Design, fabrication, and measurements of an RF-MEMS-based selfsimilar reconfigurable antenna," IEEE Transactions on Antennas and Propagation, vol. 54, no. 2, pp. 422-432, 2006.

[15] C. J. Panagamuwa, A. Chauraya, and J. C. Vardaxoglou, "Frequency and beam reconfigurable antenna using photoconducting switches," IEEE Transactions on Antennas and Propagation, vol. 54, no. 2, pp. 449-454, 2006.

[16] F. Yang and Y. Rahmat-Samii, "A reconfigurable patch antenna using switchable slots for circular polarization diversity," IEEE Microwave and Wireless Components Letters, vol. 12, no. 3, pp. 96-98, 2002.

[17] S. Raghavan, D. S. Kumar, and M. S. K. Kumar, "Reconfigurable patch slot antenna for circular polarization diversity," International Journal of Microwave and Optical Technolog, vol. 3, no. 4, pp. 419-425, 2008.

[18] Z. Harouni, L. Cirio, L. Osman, A. Gharsallah, and O. Picon, "A dual circularly polarized $2.45-\mathrm{GHz}$ rectenna for wireless power transmission," IEEE Antennas and Wireless Propagation Letters, vol. 10, pp. 306-309, 2011.

[19] Y. Tawk, J. Costantine, and C. G. Christodoulou, "A frequency reconfigurable rotatable microstrip antenna design," in Proceedings of the IEEE Antennas and Propagation Society International Symposium (APSURSI '10), Toronto, Canada, July 2010.

[20] N. Singh, D. P. Yadav, S. Singh, and R. K. Sarin, "Compact corner truncated triangular patch antenna for WiMax application," in Proceedings of the 10th Mediterranean Microwave Symposium, (MMS '10), pp. 163-165, Guzelyurt, Cyprus, August 2010.
[21] M. Ali, G. Yang, and R. Dougal, "A new circularly polarized rectenna for wireless power transmission and data communication," IEEE Antennas and Wireless Propagation Letters, vol. 4, no. 1, pp. 205-208, 2005.

[22] K. Chung, Y. Nam, T. Yun, and J. Choi, "Reconfigurable microstrip patch antenna with switchable polarization," ETRI Journal, vol. 28, no. 3, pp. 379-382, 2006. 

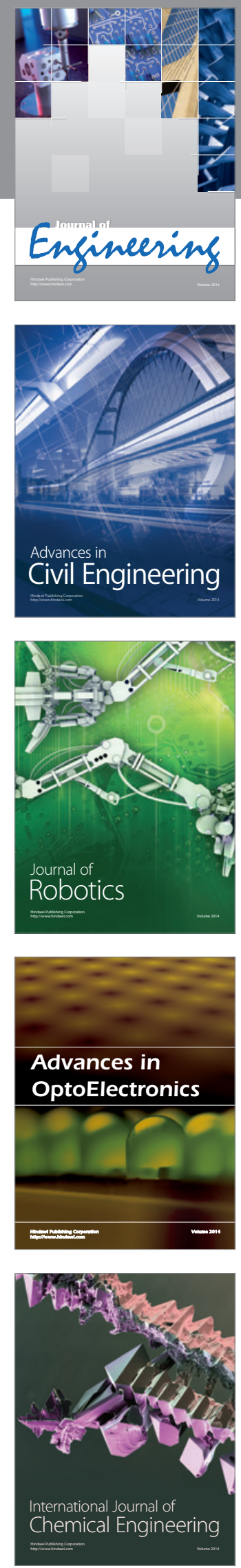

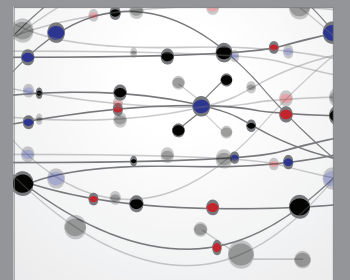

The Scientific World Journal
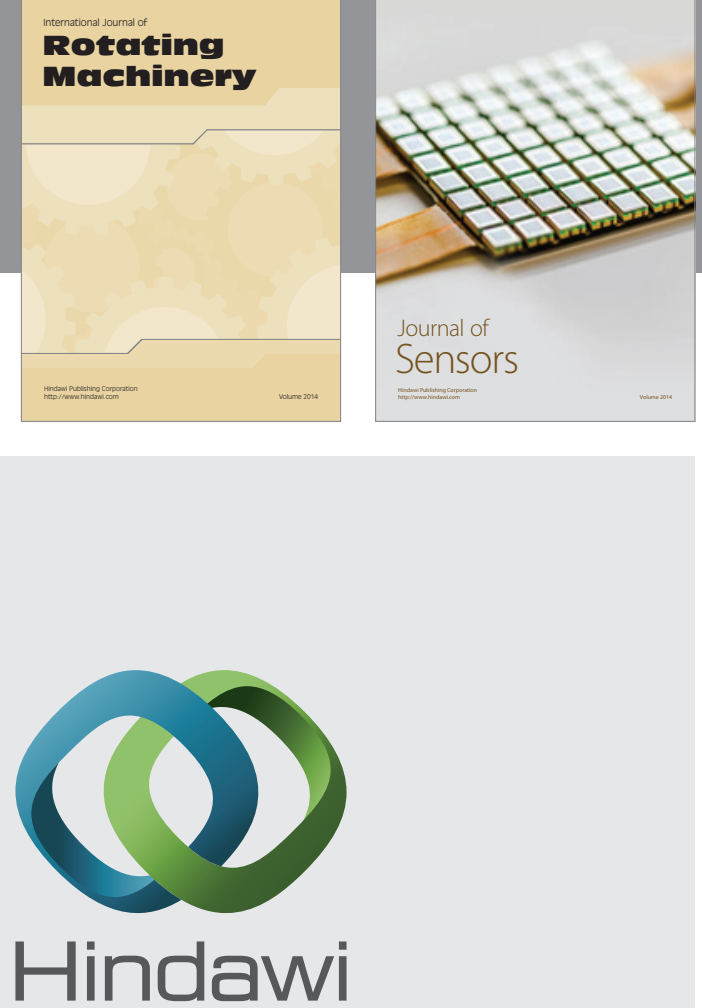

Submit your manuscripts at http://www.hindawi.com
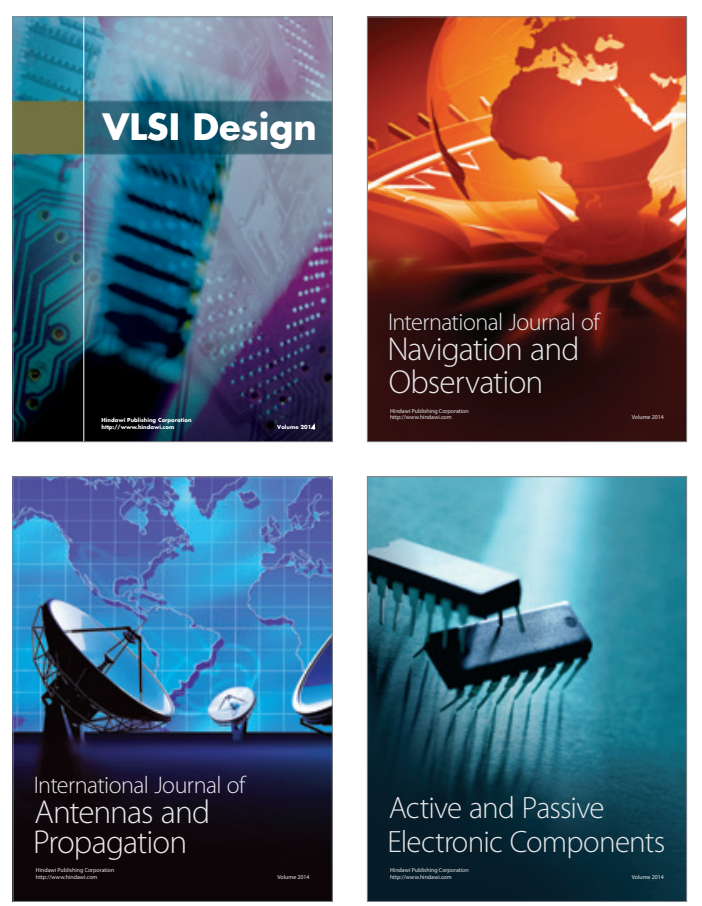
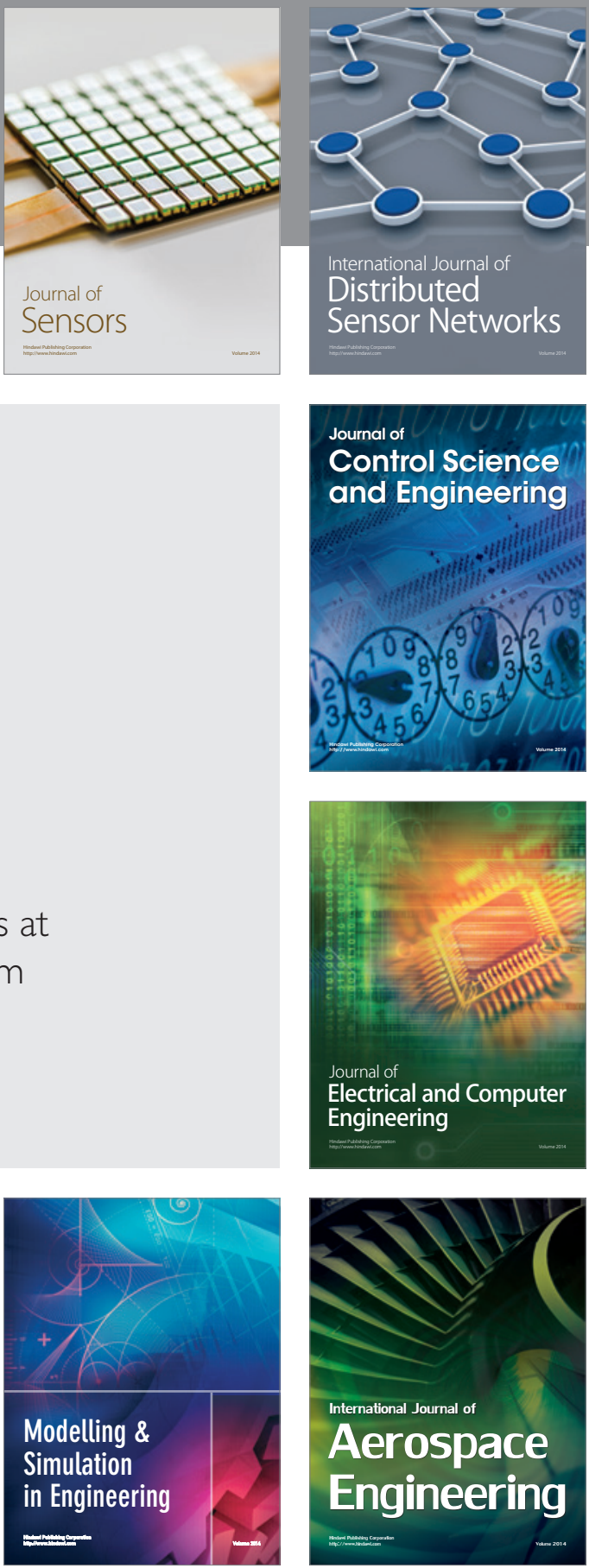

Journal of

Control Science

and Engineering
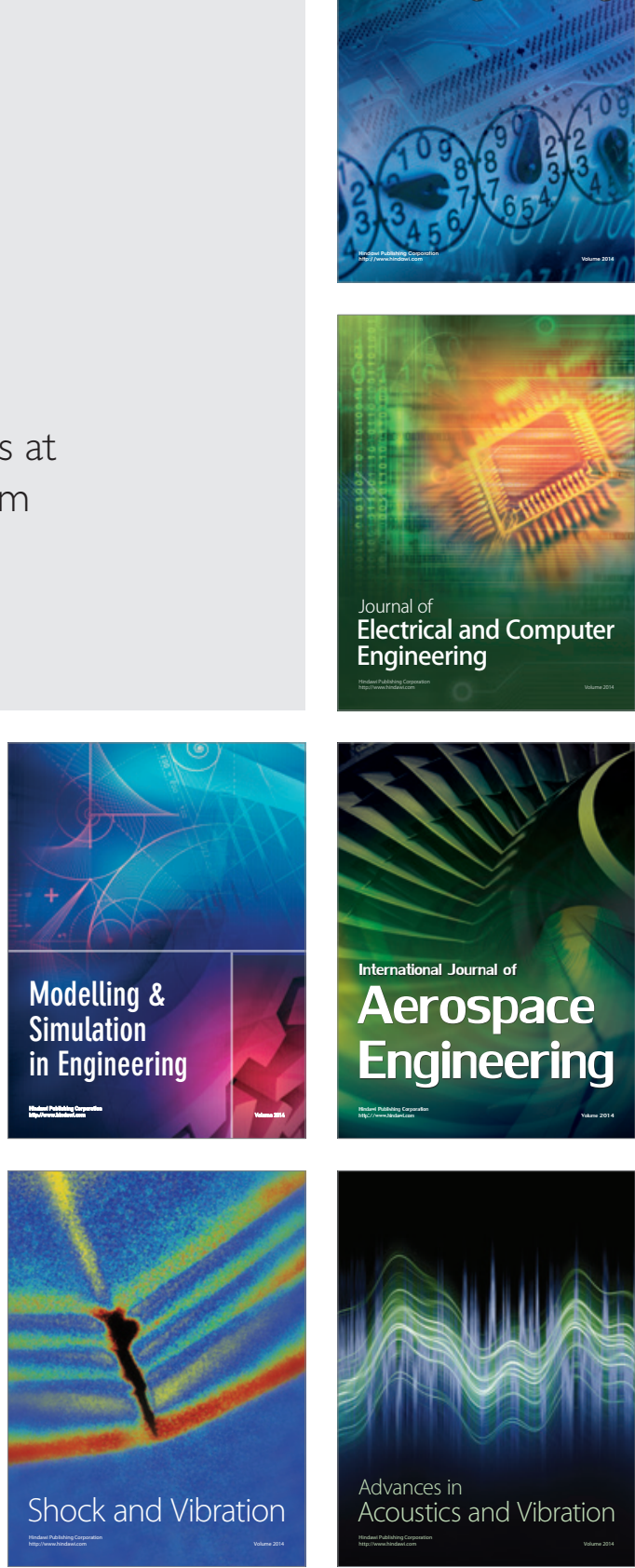